\title{
Intermediality and Theatre: Wendy Wasserstein's The Heidi Chronicles
}

\section{Scott Pound}

An American dramatist, availing herself of a sound design technique pioneered by filmmakers, weaves soul and rock songs into her plot in a way that might best be understood in terms of Roland Barthes's theory of photography. The seemingly tortured logic required to formulate Wendy Wasserstein's use of intermediality in The Heidi Chronicles (1988) belies the effortless way the properties of one medium can be integrated into the framework of another. In Wasserstein's case, a visceral aural aesthetic with great cultural currency is spun into the theatrical event in a way that both complements and competes with meanings encoded via conventional dramatic devices. In the process, the expressive resources of popular music become a powerful adjunct to the meaning-making apparatus of dramatic realism.

In the most basic sense, Wasserstein's use of recorded popular music functions as an unusual, though highly effective, form of exposition. In the play, songs by Betty Everett, The Rolling Stones, Janis Joplin, Otis Redding, John Lennon, Jefferson Airplane, and Sam Cooke perform - and in the process transform - the utilitarian task of providing background information necessary for the audience's understanding of the dramatic action. This is not background or between-the-acts music. Rather, songs, and especially their lyrics, are foregrounded as an integral part of the plot. While comparable to the usual modes of dramatic exposition (dialogue, soliloquy, prologue/chorus, and narration), Wasserstein's use of music is more subtle and efficient, capitalizing on the informational density of popular music ${ }^{1}$ to guide the audience and connect the drama to a series of cultural and historical backdrops.

But the songs do more than simply communicate information. They also, and much more dramatically, communicate somatically as resonant events in the lived experience of the audience. "Music moves us, quite literally," Stephen Davies points out, "and often we are unaware of the small motions we make in response to it." When it comes to rock 'n' roll music, "These material or 'visceral' properties of rock are registered in the body core, in the gut, and in the muscles and sinews of the arms and legs rather than in any intellectual faculty of judgment." "The power of rock and roll," Lawrence Grossberg writes in a similar vein, "is located

Scott Pound is Associate Professor of English at Lakehead University in Thunder Bay, Ontario, Canada. His research examines the intersection of poetics and new media in the twentieth century. He is currently at work on a project called "The Poetics of Intermediality," which studies cultural impacts of new media through the lens of twentieth-century vanguard poetics. 
in its affectivity, that is, in its ability to produce and organize structures of desire."4 Here we confront a very different aspect of music's communicative force, one that cannot be explained the usual way via theories of linguistic meaning (semantics), signification (semiotics), or symbolism (hermeneutics). In its appeal to supplemental dimensions of melody and rhythm - those two intensely affective qualities that make it such a visceral medium - popular music signifies in a more complex way than language alone does. The songs Wasserstein chooses not only telegraph information which the audience can use to make sense of the drama, but also provide somatic links to a wellspring of involuntary affect, Proustian madeleines evoking worlds of experience and feeling. This strange brew of information and affect creeps into the play, flowing through the mise en scène in an evanescent but very powerful way, providing us with a form of exposition that informs and moves us at the same time.

An analysis of Wasserstein's use of music in the play necessarily takes us out of the semantic/semiotic/hermeneutic fold, and the strictly textual field presupposed by literary studies methodology, into a sphere that is characterized by what I will call "intermediality": that zone of contact where the expressive resources of one medium meet those of another to form a hybrid. Plays are by definition intermedial works because they function as a hybrid of text and performance. Wasserstein takes the de facto intermediality of theatre and amplifies it by adding recorded music to the mix. At stake is not so much the originality of the technique (Wasserstein is simply adapting the rock 'n' roll film soundtrack to her own purposes), but rather the potency of it. The songs Wasserstein uses are rich in cultural references and connotations that make them excellent vehicles for expository tasks, but they also retain the power to "prick" us emotionally in much the same way Roland Barthes in Camera Lucida suggests photographs can. In other words, they also signify in unusual and unpredictable ways, affording Wasserstein a remarkably varied and sometimes unwieldy means of communicating with her audience.

What follows is divided into three parts. In the first part, I distinguish Wasserstein's use of music from theatrical convention and relate it to the way contemporary filmmakers use popular music. The second part of the essay offers a close reading of the songs featured in The Heidi Chronicles in terms of their expository and affective payoff. Because Wasserstein's use of music takes us beyond the methodological field presupposed by literary studies and into a new region of intermediality where the resources of text and music combine to produce hybrid effects, it is important to develop a corresponding theoretical framework. The third part of the essay provides such a framework for understanding the kind of intermediality Wasserstein's play creates.

\section{Popular Music and Narrative Film}

Wasserstein's confident use of classic soul and rock tracks to punctuate an episodic plot has obvious parallels with the use of similar music in dozens of 
contemporary narrative films, but it shows no obvious similarities with established theatrical convention. While drama and music have been deeply integrated since ancient times, Wasserstein's use of music has little in common with established forms of musical theatre or the contemporary tradition of intermedia experimentation pioneered by the literary and theatrical avant garde. Unlike in musical theatre, the songs in The Heidi Chronicles are not original to the play, and, although they occasionally sing along, the characters do not actually sing the songs as they would in musical theatre. Because the songs in The Heidi Chronicles are taken from recordings, they integrate themselves into and affect the narrative in a different way than songs actually sung by performers on the stage. In a musical, original songs are integrated into the drama as a part of the action. Popular recorded songs, on the other hand, exist in addition to the action. They create a new channel to supply the drama with supplemental information and affect.

Separating the image track from the soundtrack is a routine and necessary part of the filmmaking process which filmmakers have leveraged into an expressive device by exploiting the inherent dialogism of sound and image. "The moment we recognize to what degree film music shapes our perception of a narrative," Claudia Gorbman writes, "we can no longer consider it incidental or 'innocent." A simple commutation test (substituting a different piece of music for what exists on the soundtrack) proves the impact of music on image perception. Gorbman performs such a test on a scene from Truffaut's Jules and Jim when she evaluates what effects changes in musical tempo, rhythm, and instrumentation might have on the way we understand the meaning of a scene in which two people pedal their bicycles through a valley. An even better example is a sequence from Chris Marker's Letter from Siberia in which the same footage is shown three times, each time with a different accompanying soundtrack. In each case, the audience perceives the same image sequence differently. A commutation test shows that when our visual attention is engaged in concert with our aural attention, what we hear powerfully influences what we see. And when basic sound effects are augmented with familiar recorded music, a whole new dimension of meaning is added to the presentation. Music can harmonize with, provide counterpoint to, or render ambiguous what the audience sees. Whether it be diegetic (issuing from a source within the narrative) or nondiegetic (coming from the soundtrack), the mood of any music heard in a scene will be felt in relation to events of the plot. ${ }^{5}$

The power of music to influence film narrative surges with the emergence of the rock ' $n$ ' roll soundtrack in the late $1960 \mathrm{~s}^{6}{ }^{6}$ The portability of popular songs lends them particularly well to the episodic form of storytelling that characterizes narrative filmmaking. In the traditional feature film score, orchestral music waxes and wanes in the background of the audience's sensory perception, cuing responses in the audience without calling attention to itself. But, as David R. Shumway points out, rock soundtracks gregariously take center stage, often displacing the image 
as the primary focus of attention. ${ }^{7}$ Through their lyrics, rock songs add another narrative dimension to the plot, thickening scenes by adding information that can influence and compete with the diegesis. More than that, rock songs further inject a sensuous and textured aural aesthetic with strong revolutionary and countercultural overtones, one that has been variously commercialized by the recording industry and internalized by audience members as an adjunct to their own experience. In this way, rock songs tap into and activate deep-seated personal histories via nostalgia. When we add the fact that rock songs are also social texts that activate cultural and historical codes, we have a very potent supplemental mode of expression weaving its way into the narrative fabric of a film.

The potency and portability of popular music make it attractive to filmmakers for whom it represents an opportunity to connect quickly and decisively with their audience. "An audience will trust music before they will trust narrative, before they will trust actors," filmmaker Alan Rudolph notes. Filmmaker Allison Anders goes further: "It [popular music] is just the basis for communication in our culture. . . . It's so evocative and coded so deeply in our psyche, it's a whole world culture." Whether or not popular music can be a vehicle for yoking together a world audience under a single banner, it does possess genuine properties as a cultural adhesive, and other filmmakers have made similar universalizing claims: "It [popular music] is part of everybody, [it] is a universal language," says Bob Last. The inflated language of such claims notwithstanding, popular music and films make a powerful, mutually sustaining blend in the rock ' $\mathrm{n}$ ' roll era. Some filmmakers begin to think in soundtracks. Musicians, prompted by the advent of music videos, begin to think increasingly in visual terms. The rock soundtrack and the "three-minute movie" have been integrated ever since. As Quentin Tarantino puts it, "The use of music in movies is one of the most cinematic things you can do."

It makes sense that a playwright would pick up on all of this given the similarities between film and theatre, but the cinematic use of popular music, while it does tell us a lot, by no means tells us everything we need to know about Wasserstein's use of music in her play. Her use of music is subtly different and, for her own purposes, more effective than the typical use made of music in film. Part of this is due simply to the difference between film and theatre. In a film, music often performs media-specific functions that it could not perform in the theatre. A typical Hollywood film contains between 1000 and 2000 shots spliced together in a nonlinear sequence. The inherent disjunctiveness of the filmmaking process is compensated for in large part by editing techniques and sound design which can give the impression of coherence despite routine violations of the unities of time, place, and action. For example, music played continuously across the cut can be used to tie together discordant footage, signaling via aural means a connection where no obvious visual continuity exists. In a similar way, music added to montage sequences provides a temporally and spatially discontinuous series of images with 
an aurally endowed sense of cohesion. Because Wasserstein does not need music to vouchsafe continuity, she is free to put it to other uses, like exposition.

\section{The Heidi Chronicles}

As its title implies, Wasserstein's play tells the story of a protagonist named Heidi, a baby-boomer who comes of age in the late 1960s. The plot is unusual, however, in that it represents Heidi's conflict, not with other characters so much as with her times. Heidi's attempt to find meaning and fulfillment in her life is forever at odds with the changing culture of post-war America. As a sixteen year old in the first scene, she is ahead of her time and finds the courtship rituals of late adolescence embarrassing and offensive. Three years later, Heidi has developed a scrappy and tough exterior to weather the sexual revolution but still finds herself caught out by a frank invitation to sex from an aggressive, though charismatic, male character. In her next incarnation, Heidi pops up at a feminist meeting only to find her broad-based humanism judged as soft by the assembled women. And so it goes. For all her intelligence, wit, and strength of character, Heidi is perpetually out of synch with her era. The plot of the play is designed to register the conflict between Heidi's steadfast best intentions and the fickle climate of the times. Each of these pivotal moments in the action is matched with a song or two.

Wasserstein's episodic plot presents short vignette-like scenes plucked at regular intervals from the story. In all, the eleven scenes and two prologues span a time period of twenty four years, from 1965 to 1989. As an attempt to dramatize a protagonist's conflict with the pace of cultural change rather than with her family or community, The Heidi Chronicles must provide a wealth of background information with the utmost efficiency. Where her predecessors in the American tradition might have chosen narration to fill such a large information gap (plays like Our Town and The Crucible quickly come to mind), Wasserstein chooses popular music. Each episode of the plot represents a new era in both Heidi's life and the social history of the times. For the scenes to succeed, the audience needs to understand the web of personal and sociocultural implications that attach to the action. While Wasserstein also uses dialogue, setting, and costume to cue the audience to key elements of the action and its relation to historical realities, music provides the best part of the background information.

In Scene One, we see Heidi and her friend Susan at a high-school dance. The year is 1965; "The Shoop Shoop Song (It's in his Kiss)" (1964) ${ }^{9}$ plays over the sound system as the girls sing along and sway to the music. The opening lines of the play consist of lyrics from the song, sung by Heidi and Susan.

SUSAN: Is it in his eyes?

HEIDI: Oh, nooooooo, you'll be deceived. 
SUSAN: Is it in his eyes?

HEIDI: Oh, no, he'll make believe. ${ }^{10}$

Here the call and response structure of the song is used to enact a dialogue between a naif in search of the sign of true love (Susan) and a cynic who counsels on the deceptiveness of men (Heidi). Right away we are brought up to speed on Heidi and Susan and given clues as to the nature of their relationship. Susan is boy crazy; Heidi is aloof and wise for her years. But the dialogism of the song also reveals an important conflict that throws into relief Heidi's real predicament: the lack of a functional gender ethic with which to assert her autonomy and navigate sexual situations with dignity and the consequent need to suppress her resistance and conform to patriarchal norms. Susan blithely inhabits a social universe defined by a patriarchal gender ethic which entails subordinating herself to men and sexualizing her appearance by rolling up her skirt. All of this in pursuit of the real goods and the true revelation of love: "his kiss!" Heidi rejects this ethic and is left with nothing in its stead. The resulting conflict is between the two equally marginalizing points of view thematized in "The Shoop Shoop Song": passive naïf and uninvolved cynic. ${ }^{11}$ The first sequence of action ends with Susan scolding Heidi for lacking the requisite awareness of the prevailing gender ethic:

SUSAN: Heidi, we're at a dance! You know, girl meets boy.

They hold hands walking in the sand. Then they go to the

Chapel of Love. Get it?

HEIDI: Got it. ${ }^{12}$

At this point, we are just ninety seconds into the scene (less than two pages of dialogue), but our depth of knowledge about the characters and their situation is already substantial due to the amount of background information supplied by the song.

The next song at the dance ("(I Can’t Get No) Satisfaction" (1965), ${ }^{13}$ hereafter "Satisfaction") is a "Lady's Choice," which sends Susan into a frenzy of primping and skirt rolling. As the quaint hook and tinkling percussion of "The Shoop Shoop Song" is replaced by the raw grind and fuzz-box guitar of "Satisfaction," the mood of the scene changes dramatically. The wholesome ethos of "The Shoop Shoop Song" fades, and "Satisfaction" brings in a frustrated and rebellious tone that evokes the turbulent events of the mid-1960s. ${ }^{14}$ Only a year separates these two recordings, but the transition from one to the other is pure culture shock. "The Shoop Shoop Song" is something of an oldie right out of the box in 1964, evoking an avid, though chaste, ethos of love-longing reminiscent of the 1950s. Just one year later, the Rolling Stones break onto the American scene with a controversial 
smash hit that advances the theme dramatically from courtship to flagrant boredom, numbing alienation, and the suggestion of casual sex. The affective load of these two very well-known songs is such that juxtaposing them allows the audience to get a mediated sense of the jarring cultural changes in America circa 1965. How mediated? When we consider firstly that popular songs are a direct and powerful index of cultural attitudes toward issues like love, sex, and money; secondly that smash hits become deeply embedded in our personal and cultural memory; and thirdly that music is cross-coded in memory with events from specific times in our lives, we can begin to understand how resonant the medium of popular music can be, despite its mediate status. ${ }^{15}$

At this juncture in the play Susan and Heidi part for the night. Heidi sits down and pulls out, of all things, a book. "Satisfaction" ends and another Rolling Stones' song, "Play With Fire" (1965), ${ }^{16}$ comes over the sound system. This time, Wasserstein uses a song as a window into Heidi's mind and a vehicle for dramatic irony. According to the ethic of the dance, Heidi is a sitting duck, prey for eager boys on the prowl. Little do the boys know that they are the hunted. "Don't play with me, 'cause you playing with fire," the sinister chorus warns. But the song sets the audience up by creating a false expectation. In accordance with the musical cue, we immediately expect to see a hapless boy approach Heidi and get burned, but instead we see Peter approach Heidi and connect with her almost instantly. As they banter, "The Shoop Shoop Song" (somewhat implausibly) comes on again and Peter asks Heidi to dance. "Certainly," the formerly reticent Heidi says.

The first time we hear "The Shoop Shoop Song," its purpose is to establish the atmosphere and ethos of the high school dance circa 1965 and to gloss the relationship between Heidi and Susan. In addition to providing important background information, the song, true to its status as an "oldie," bathes the scene in nostalgia. At this point, Wasserstein runs the risk of forfeiting her drama to the canned sentiment of the song, but she finds an effective means to counteract that. She has Peter and Heidi mock the song in their dialogue and in the process gets even more mileage out of it as a vehicle for characterization:

PETER: Ahhh! "The Shoop Shoop Song.” Baroque but fragile. HEIDI: Melodic but atonal.

Peter and Heidi's ironic comportment to the song establishes a new ethos that will come to define Heidi's character: detached, sardonic, and sometimes stranded observer of life. At a stroke, Heidi becomes a more complex character and the potentially insidious nostalgic overtones of the song are kept in check. By bringing the song from the background to the foreground of the scene, Wasserstein pulls out additional valences of plot and character, allowing Heidi to pivot from the world implied by Susan's behavior to the more sophisticated world evoked by Peter. As 
Peter and Heidi improvise an interpretive dance to the song, they begin to sing along:

PETER: How 'bout the way he acts?

HEIDI: Oh, noooo, that's not the way.

PETER: And you're not listenin' to all I say.

If you wanna know if he loves you so...

Takes Heidi's waist and dips her.

PETER: It's in his kiss.

HEIDI \& PETER: Oh, yeah! It's in his kiss! ${ }^{17}$

Once again, the dialogism of the song cues us to a crucial aspect of Heidi's character. She is both powerful and vulnerable. Her intelligence allows her to mock and refuse her culture, but she is at the same time more than receptive to the charms of men, especially smart ones. Intelligent men weaken her defenses, as we see at the end of the scene with Heidi in a prone position singing, albeit ironically, from the same songbook as Susan.

Scene Two takes place three years later, also at a dance - this time a "Eugene McCarthy mixer." As the scene opens, "Take a Piece of My Heart" (1968) by Janis Joplin and Big Brother and the Holding Company can be heard. The song, along with a "Eugene McCarthy for President" poster, informs the audience that the plot has taken a temporal leap from the mid to the late 1960s. At the same time, it continues the supply of vital information about Heidi's character and motivations. Students of the play who do not pay careful attention to the music often come to the conclusion that Heidi is a feminist icon: a strong, educated, self-determined woman in complete control of her destiny. That's not really true, and it is the song that cues us to the more complex reality of Heidi's character. She's a strong, educated, self-determined woman with a vulnerable side that puts her at a disadvantage with men, especially intelligent, charismatic men like Peter and the man she's about to meet, Scoop Rosenbaum.

The lyrics of "Take a Piece of My Heart" and the overall ethos of the song reflect a vision of female strength as "toughness."

Didn't I make you feel like you were the only man-yeah!

Didn't I give you nearly everything that a woman possibly can Honey, you know I did!

And each time I tell myself that I, well I think I've had enough,

But I'm gonna show you, baby, that a woman can be tough.

But it is a kind of toughness that applies to things that can "take a licking and keep on ticking." The speaker of the song taunts her man with a masochistic command to 
Take another little piece of my heart now, baby!

Oh, oh, break it!

Break another little bit of my heart now, darling, yeah, yeah, yeah. ${ }^{18}$

Scoop will do just that. As the scene progresses, he chips away at Heidi's surface toughness, putting her more and more on the defensive, his aggressiveness a prelude to his invitation to impromptu sex. At the end of the scene, when Heidi actually leaves with Scoop, we're not sure whether we should applaud or hang our heads. The music that plays as the scene ends and Heidi and Scoop exit together-Jefferson Airplane's "White Rabbit" (1967) ${ }^{19}$ — helps us decide. With its seductive melody layered over a march rhythm and psychedelic lyrics, the strange and dissonant "White Rabbit" plays perfectly to the conflicted action taking place on stage, providing both commentary and counterpoint, a hint of foreplay coupled with a sense of bewilderment and foreboding, Alice in Wonderland style.

Scene Three takes us ahead another two years to 1970, and once again a song opens the scene, but this time it's not a dance. It is a meeting of the Huron Street Ann Arbor Consciousness-raising Rap Group, and the song is Aretha Franklin's cover of Otis Redding's "Respect," ${ }^{20}$ recorded in 1967. The Civil Rights Movement has helped bring African American music into the mainstream, and the women's movement has seized on one of the biggest cross-over hits (and Aretha Franklin's first \#1 single) as its battle cry. As the women prepare for the meeting and belt out the lyrics, a number of things are established. Feminism's second wave is in full swing and women are organizing. "Respect" is meant to thematize two strands of the narrative in this scene: the political quest for female autonomy with dignity and Heidi's own personal search for autonomy with dignity in her day-to-day affairs. True to her nature as an observer, Heidi chooses not to participate in the meeting, using her old excuse that she "came with a friend." The most militant member of the group, Fran, calls Heidi out on this and challenges her to lay her cards on the table: "Heidi, either you shave your legs or you don't." ${ }^{21}$ Heidi comes clean about her on-again, off-again relationship with Scoop, and is embraced by the group for being honest and candid. As the scene winds down, Jill (the least militant member of the group) gathers the group in a circle and leads them in a rendition of her favorite camp song, which Fran finally interrupts with a "Fuck this shit" and puts Aretha back on. The scene ends with the group singing along again to "Respect."

Of all the songs Wasserstein uses in the play, "Respect" is the most fraught with irony. Both Wasserstein and the women of the rap group are using the song to endow this meeting with a certain ethos, only it's not the same one. The women want their gathering to be steeped in an atmosphere of power and assertiveness, which the song provides ready-made. But the conditions under which the song functions are suggestive of other meanings that Wasserstein will emphasize via 
dramatic irony. When Wasserstein has the women sing a buoyant camp song in between the two renditions of "Respect," we are immediately reminded that this is a group of trendy, elite, white, suburban feminists who appropriate an AfricanAmerican anthem in bad faith as an ideological prosthesis designed to lend their enterprise a sense of power and credibility that it might otherwise lack. In this way, the music primes us with background information, telling us that we are meant to question these women and their commitment to feminism.

Questioning the use of the song might also lead us to wonder about the song itself, which brings us to still deeper ironies. "Respect" is, after all, a song written by a man about a male speaker who wants sex on demand from his female partner. That Aretha Franklin can resignify the song by simply singing it (and singing it differently) says a lot about the ideological plasticity of popular music and the complex status of rock music in feminist practice.

As Robert Christgau has observed, rock music can give women a source of political leverage:

Insofar as the new feminism results from a certain style of heightened political awareness that began with the civil-rights movement, it can be said to have some of its roots in the adolescent rebellion symbolized by rock and roll.... Women like rock not only because it has human value but also because some of that human value is, or has been, good for them as women. [Nevertheless,] because rock draws upon traditional folk attitudes dating back (at least) to African tribal dances and Scottish folk ballads . . . its sexual energy, like all formalized sexual energy I know about, is also sexist energy. It posits the classic pattern of man the pursuer/actor and woman the pursued/acted-upon. ${ }^{22}$

Aretha Franklin's appropriation of "Respect" is a symbolic reversal of a power dynamic endemic to patriarchy. The Huron Street Ann Arbor Consciousness-raising Rap Group's appropriation of Aretha Franklin's version of "Respect" is very different. In highlighting their use of the song as an article of bad faith, Wasserstein purposefully invokes both the gender and racial implications of this double bind.

Several scenes and a decade later, Scoop has married, Peter is out of the closet, and Heidi finds herself in another room full of women, this time a baby shower for Scoop's wife, Lisa. Once again the music telegraphs a temporal and cultural leap. John Lennon's quiet, utopian anthem "Imagine" $(1971)^{23}$ signals to the audience that the ebullient militancy that characterized the rap group is long-gone and that Heidi's shape-shifting friends have cottoned to new trends and other forms of fulfillment. Child rearing and high paying career moves are the order of the day. Having opted for neither, Heidi continues to orbit the world of her friends like a 
foreign satellite, recording everything but regarded with suspicion. The idealistic atmosphere provided by the song belies the harsh facts that Scoop is cheating on his pregnant wife, John Lennon has just been assassinated, and Susan has sold her soul to Hollywood. We could continue to call this dramatic irony, which it is, but in this scene the utopian ethos rises almost to the status of a character acting as a foil to the reality of the other characters' lives. Amidst all this, Heidi stands out as a beacon of lonely integrity, which she will later parody in a speech at her private school alma mater.

As the play moves into its second and final act and the need for background information diminishes, so too does Wasserstein's use of music, but she does not abandon it. Having woven the songs tightly into her plot in the first act, Wasserstein makes some of them serve double duty as sonic motifs to unify the plot and give a sense of continuity over plot time. In early scenes the songs provide background information and dramatic irony; in later scenes they are repeated, not for expository effect, but for dramatic affect. In a late scene, Heidi and Peter reprise "The Shoop Shoop Song" and reaffirm their love for one another as friends. The song and their ironic experience of it have become an emblem of their shared traits; it evokes the tenor of their relationship as nothing else can. Here Wasserstein allows the nostalgia to pour forth without interference. The play ends on another nostalgic note with Heidi reprising Sam Cooke's "You Send Me" (1957), ${ }^{24}$ a song she danced to with Scoop in another poignant scene in which, having just married Lisa, Scoop confessed his enduring romantic love for Heidi. This time Heidi sings "You Send Me" to her newly adopted daughter as she rocks her to sleep and the lights fade out. In these instances, the songs evoke nostalgic emotions associated with the plot and the characters, but residing equally in the lived experience of the audience. Whereas early on the songs primarily informed the audience, now (supposing the songs resonate in the right way) the songs make an emotional appeal.

\section{Music and Language}

So far, my analysis of Wasserstein's play shows that popular music can be used to facilitate important dramatic tasks like exposition, characterization, and dramatic irony. Less straightforward but equally important is the theoretically vexed and complex question of how music communicates. Are the words and the music of songs distinct systems or are they an integrated symbolic practice? If distinct, does music signify in a way fundamentally different from words? Can the affective load of a song be reduced to a linguistic message, or does it somehow outstrip any attempt to reduce it to linguistic signs? These are important questions to ask because Wasserstein's use of music takes us beyond the methodological field presupposed by literary studies and into a new region of intermediality where the resources of text and music combine to produce hybrid effects. In this final section of the paper, I examine this confluence and the problem music seems to pose for 
linguistic processing.

It is a peculiar capability of music to communicate like a language and yet also remain impervious to linguistic signification. ${ }^{25}$ As such, its use in literary contexts opens up questions about signification and meaning. "Music is similar to language. But music is not language,." Theodore Adorno tells us. "Its similarity to language points to its innermost nature, but also toward something vague. The person who takes music literally as language will be led astray by it." 26 That "something vague" is music's fabled ambiguity. Language and music are both comprised of rhythmical sound sequences that unfold in time; both are composed of specific segmental (phonemes and pitches) and suprasegmental (prosody and scales) elements ${ }^{27}$; yet, music lacks the referential and denotative capacity of language, a fact that has led scholars to cite ambiguity as "a key element of the grammar and aesthetic of music." 28 Music's ambiguity leads Adorno to contrast it with language. "In comparison to signifying language, music is a language of a completely different type. What music says is a proposition at once distinct and concealed," he notes early on in "Music, Language, and Composition." Later in the essay, Adorno takes a stab at a positive definition. The result is a haiku-like piece of critical poetry: "to be musical means to innervate the intensions that flash forth." ${ }^{29}$

Music harbors other paradoxes too. Every individual experiences music differently, and yet music at the same time constitutes sociality: "Music, we could say, provides us with an intensely subjective sense of being sociable," Simon Frith writes. "Whether jazz or rap for African Americans or nineteenth-century chamber music for German Jews in Israel, it both articulates and offers the immediate experience of collective identity." ${ }^{30}$ To use popular music in a performative context, then, is to tap into an aspect of audience consciousness both deeply subjective and resolutely social and historical. People carry popular music around inside themselves, and it resonates personally. At the same time, songs are social texts. They record specific responses to particular times and places which are then internalized by large audiences. When we encounter songs in a play, they resonate as both subjective experience and a form of cultural memory. This especially potent and complex form of meaning-making capitalizes on the unique capabilities of music to signify, sometimes wildly, as both text and performance.

This paradoxical element of music seems to be what Jacques Attali means by his term "operationality":

All music can be defined as noise given form according to a code. ... Listening to music is to receive a message. Nevertheless, music cannot be equated with a language. Quite unlike the words of a language — which refer to a signified - music, though it has 
a precise operationality, never has a stable reference to a code of the linguistic type. It is not "a myth coded in sounds instead of words," but rather a "language without meaning."

This does not mean that music is meaningless, but rather that music itself, considered here independently of the lyric, attains much of its meaning by other than linguistic channels.

The signification of music is far more complex [than linguistic communication]. Although the value of a sound, like that of a phoneme, is determined by its relations with other sounds, it is, more than that, a relation embedded in a specific culture; the 'meaning' of the musical message is expressed in a global fashion, in its operationality, and not in the juxtaposed signification of each sound element. ${ }^{31}$

Attali's point, which, like Adorno's, presupposes classical form, is nonetheless echoed by rock sociologist Simon Frith, who argues that "the 'meaning' of music describes, in short, not just an interpretive, but a social process: musical meaning is not inherent (however 'ambiguously') in the text." 32 In addition to "the text" of music, we must also pay attention to the wild card element of musical ethos, the appeal that music makes via seemingly non-referential means, via pathos. As noted in the analysis of the play, there are times when Wasserstein must curtail this aspect of the music she uses (e.g. "The Shoop Shoop Song"), times when she subverts it ironically (e.g. "Respect," "Imagine"), and times when she allows the ethos of the song to take over (e.g. "Satisfaction," and "You Send Me"). In this last case, she forfeits control of the drama to meanings that emerge by other than linguistic means.

For many theorists of modernity and postmodernity, music's recalcitrance to meaning or significance as conceived linguistically stands as an emblem of a force in human culture that signifies, but in a nondiscursive, nonreferential way. As in Nietzsche's and Kristeva's work, music (particularly rhythm) bears witness to drives (or "formative forces" as Nietzsche called them) ${ }^{33}$ that structure and inform awareness in ways that prefigure language. Kristeva substantially refines Nietzsche's notion of "Dionysian rhythm" with her concept of the chora: "The chora precedes and underlies figuration and thus specularization, and is analogous only to vocal or kinetic rhythm." ${ }^{34}$ Other theorists have identified a similarly intractable quality that exists prior to understanding but testifies nonetheless to a resonant and forceful articulation. Rodolphe Gasché's designation of the "absolutely singular" refers to a dimension of texts that is irreducible to any one possible meaning. ${ }^{35}$ Roland Barthes's evocation of "the neutral" as a "stubborn affect" 36 similarly gestures 
toward a form of articulation that eludes paradigmatic understanding but registers in feeling. And Deleuze and Guattari make their own forceful case for a kind of articulation that eludes signification,

just as there are asemiotic expressions, or expressions without signs, both on the strata and on the plane of consistency. The most that can be said for significance is that it characterizes one regime, which is not even the most interesting or modern or contemporary one, but is perhaps only more pernicious, cancerous, and despotic than the others, and more steeped in illusion than they. ${ }^{37}$

Each of these documented sightings of alternative forms of articulation testifies to the existence of non-linguistic forms of meaning-making, but music still seems to evade us. It is, as the experimental psychologist and cognitive scientist Steven Pinker observes, "an enigma." ${ }^{38}$ It seems to push us toward a semantic/semiotic/ hermeneutic dead end.

For a last alternative conceptual model that describes how articulations can affect us in ways that escape linguistic processes, we should consult Barthes's work, not on music, but rather on photography. ${ }^{39}$ In Camera Lucida, Barthes describes two elements in the way we experience photographs. The first element - the studium - is the kind of meaning that emerges when one's knowledge and culture come to bear on various aspects of the photograph, willfully assigning coordinates to the signs that are present and fleshing out their connotations within the cultural context they presuppose. In relation to a photograph taken in 1979 during the Nicaraguan rebellion, Barthes summarizes the "body of information" referred to as follows: "rebellion, Nicaragua, and all the signs of both: wretched un-uniformed soldiers, ruined streets, corpses, grief, the sun, the heavy-lidded Indian eyes. Thousands of photographs consist of this field. . . What I feel about these photographs derives from an average effect, almost from a certain training." ${ }^{40}$ The studium is the way that one participates culturally in the figures of the photograph. This is the kind of meaning we ascribe to a song when we situate it within its cultural and historical milieu - for instance when we understand a song like "(I Can't Get No) Satisfaction" as a reflection of the spirit of the times circa 1965, indexing its message of sexual frustration, anti-commercialism, and countercultural revolt as a normative 1960s statement.

The second element "will break (or punctuate) the studium. . . . It is this element which rises from the scene, shoots out of it like an arrow, and pierces me." Barthes calls this second element the punctum. Involuntary, it evokes an emotional response that "pricks." Wedged between the image and the thing it represents is a small epiphany or recognition that startles and captivates us; our faculty of understanding cannot quite master the thing that stubbornly attracts our attention 
despite ourselves. ${ }^{41}$ In such cases, our preoccupation with knowing the photo is short-circuited by our actual experience of it.

Something similar often happens with music when a particular affective power wells up in our experience and short-circuits all the predictable cultural elements that attach to a particular song, the way "(I Can't Get No) Satisfaction" might, for a particular listener, shed all that 1960s cultural baggage and resonate contemporaneously for a subject experiencing a completely different set of desires. In the case of popular music, the punctum is often a more specific vocalic or rhythmic anomaly that eclipses the lyrics with a force more compelling and difficult to master. To adapt what Barthes says of photography, "the anticipated essence of the Photograph [/Song] could not ... be separated from the "pathos" of which, from the first glance [/hearing], it consists." ${ }^{42}$ In Camera Lucida, Barthes reports being torn between two languages: one critical, the other expressive. In a similar way, the songs in The Heidi Chronicles span two logics: one informational, the other affective. Music's putative flight from signification into experience takes us from a textual logic into a performative one where meaning is a function, not of the singular logic of textuality, but of an intermedial logic in which textual signification combines with other modes of cultural expression to produce complex and compelling effects. Wasserstein's use of music in The Heidi Chronicles participates in a textual logic but is not limited by that logic. The songs also register as evocative and resonant events, a-signifying signs that eclipse the semiotic load of an utterance.

The ability of music to tap emotion springs from the fact that music is neurologically cross-coded with memories of events. Our emotional centers are in turn connected to the area of the brain responsible for motor movement. "Not all emotional activities lead to motor movements, but many of the important ones do," notes Daniel Levitin. ${ }^{43}$ Each audience member's previous experience of a song plays a large role in determining what kind of background information will be provided. At the same time, the popularity of popular music means that it is also notable as a form of collective experience in which people share in the particular ethos of a song. In this way, popular songs both consolidate and diffuse experience in ways impossible to track down and interpret. Each song is therefore tremendously overdetermined and a kind of bullet straight to the heart.

In a performance of The Heidi Chronicles, the affective, experiential dimensions of the songs are the first to hit the audience, inducing heightened emotional states and affective involvement in the action of the play. Without really spelling things out for us, the songs instantly conjure entire worlds of experience that are temporally bound. Wasserstein capitalizes on this capacity of music to function as a wellspring of involuntary affect at the same time that she also leverages the lyrics into her plot as a secondary form of exposition and commentary. The combination of these two modes of meaning-making - one informational, the other experiential; one textual, the other performative-forms a hybrid, and "the hybrid or meeting of 
two media," Marshall McLuhan reminds us, "is a moment of truth and revelation from which new form is born." 44

\section{Notes}

1. By "popular music" I mean simply music recorded for consumption by a mass-market audience, not "pop" music - an often-derided sub-format, the stock in trade of which is the single, recorded and arranged with maximum radio play in mind. That popular music can function as a vehicle for cultural knowledge and information is confirmed by its use in pedagogical situations. See, for example, B. Lee Cooper, "Popular Music: An Untapped Resource for Teaching Contemporary Black History," The Journal of Negro Education 48.1 (1979): 20-36.

2. Stephen Davies, "Rock versus Classical Music," The Journal of Aesthetics and Art Criticism 57.2 (1999): 197.

3. Bruce Baugh, "Prolegomena to Any Aesthetics of Rock Music," The Journal of Aesthetics and Art Criticism 51.1 (1993): 24.

4. Lawrence Grossberg, "The Politics of Youth Culture: Some Observations of Rock and Roll in American Culture," Social Text 8 (1983-84): 104.

5. Claudia Gorbman, "Narrative Film Music," Yale French Studies 60 (1980), 183, 190ff, 198.

6. The Graduate (1967) is recognized as the first film to use recorded popular music in place of an orchestral film score. Other notable films that extend and develop the practice include Easy Rider (1969), American Graffiti (1973), The Big Chill (1983), Dirty Dancing (1987), and a veritable cornucopia of other nostalgia, avant-garde, youth culture, and rock 'n' roll culture films.

7. David R. Shumway, "Rock 'n' Roll Soundtracks and the Production of Nostalgia," Cinema Journal 38.2 (1999): 37.

8. Jonathan Romney and Adrian Wootton, Celluloid Jukebox: Popular Music and the Movies Since the 50s (London: BFI Publishing, 1995) 119, 120, 125.

9. Rudy Clark, "The Shoop Shoop Song." Perf. Betty Everett. The Shoop Shoop Song Album (West Conshohocken, PA: Collectibles, 2000).

10. Wendy Wasserstein, The Heidi Chronicles and Other Plays (New York: HBJ, 1990) 162.

11. Anyone familiar with "The Shoop Shoop Song" will know that Wasserstein exercises a fair amount of poetic license in her use of the song for dramatic purposes. The supposed opposition between naïf and cynic is only apparent because the ostensible cynic is just as naïve in her longing for that same kiss.

12. The Heidi Chronicles, 164.

13. Mick Jagger and Keith Richards, "(I Can’t Get No) Satisfaction,” Out of Our Heads (New York: Abkco, 2002).

14. In 1965, Malcolm X was assassinated on February 21; on March 28, 25,000 demonstrators for civil rights marched from Selma, AL, to the state capitol in Montgomery, challenging the state to end racial discrimination in voting rights and segregation. 15,000 students marched in Washington, protesting the war in Vietnam on April 17. While U.S. forces, previously in Vietnam only as military advisers, were authorized for combat for the first time on July 8, President Johnson sent 50,000 more troops to Vietnam on the 28th, and the Watts Riots erupted in Los Angeles from August 15-20.

15. See Daniel Levitin, This is Your Brain on Music: The Science of a Human Obsession (New York: Dutton/Penguin, 2006) especially Chapter 5.

16. Mick Jagger and Keith Richards, "Play With Fire," Out of Our Heads (New York: Abkco, 2002).

17. The Heidi Chronicles 166, 167.

18. Janice Joplin, "Take a Piece of My Heart," Cheap Thrills (New York: Sony, 1995).

19. Grace Slick, "White Rabbit," Surrealistic Pillow (New York: RCA, 1967).

20. Otis Redding, "Respect," Perf. Aretha Franklin. I Never Loved a Man the Way I Love You (New York: Atlantic, 1967).

21. The Heidi Chronicles 180.

22. Robert Christgau, "Look at that Stupid Girl," The Faber Book of Pop, eds. Hanif Kureishi and Jon Savage (London: Faber, 1995) 366.

23. John Lennon and the Plastic Ono Band with the Flux Fiddlers, "Imagine," Imagine (London: 
Apple, 1971).

24. Sam Cooke, "You Send Me" (New York: Abkco, 1957).

25. In terms of neural circuitry, "the most parsimonious explanation is that music and language do, in fact, share some common neural resources, and yet have independent pathways as well. The close proximity of music and speech processing in the frontal and temporal lobes, and their partial overlap, suggest that those neural circuits that become recruited for music and language may start out life undifferentiated.... With increasing experience and exposure, the developing infant usually creates dedicated music pathways and dedicated language pathways" (Levitin 125).

26. Theodore Adorno, "Music, Language, and Composition," trans. Susan Gillespie. The Musical Quarterly 77:3 (1993): 401.

27. Mireille Besson and Daniele Schön, "Comparison Between Language and Music," The Cognitive Neuroscience of Music, eds. Isabelle Peretz and Robert Zatorre (Oxford: Oxford U P, 2003) 272.

28. "Comparison Between Language and Music," 272. Rita Aiello "Music and Language: Parallels and Contrasts," Musical Perceptions, eds. R. Aiello and J. Sloboda (New York: Oxford U P, 1994) 40-63.

29. Adorno, 401, 403. The relationship in songs between language and music, text and tune, is a topic of research in the field of memory and cognition. Some researchers have argued that lyric and melody are integrated in memory (See Mary Louise Serafine, Robert G. Crowder, and Bruno H. Repp, "Integration of Melody and Text in Memory of Songs," Cognition 16 (1984): 285-303). More recent evidence suggests "music and language components maintain autonomy in perception" (Isabelle Peretz, Monique Radeau, and Martin Arguin, "Two-way Interactions Between Music and Language: Evidence from Priming Recognition of Tune and Lyrics in Familiar Songs," Memory \& Cognition 32.1 (2004): 142-152). That words combine with notes in songs to give the impression of fusion nonetheless seems indisputable.

30. Simon Frith, Performing Rites: On the Value of Popular Music (Cambridge: Harvard U P, 1986) 273. As John Blacking writes, "Because music is concerned with feelings which are primarily individuals and rooted in the body, its structural and sensuous elements resonate more with individuals' cognitive and emotional sets than with their cultural sentiments, although its external manner and expression are rooted in historical circumstances," A Commonsense View of All Music (Cambridge: Cambridge U P, 1987) 129.

31. Jacques Attali, Noise: The Political Economy of Music, trans. Brian Massumi (Minneapolis: $\mathrm{U}$ of Minnesota P, 1985) 25.

32. Frith 250 .

33. Friedrich Nietzsche, The Birth of Tragedy and The Genealogy of Morals, trans. Francis Golffing (New York: Doubleday, 1956) 26.

34. Julia Kristeva, Revolution in Poetic Language, trans. Margaret Waller (New York: Columbia U P, 1984) 26.

35. Rodolphe Gasché, The Wild Card of Reading: On Paul de Man (Cambridge: Harvard U P, 1998) $181 \mathrm{ff}$.

36. Roland Barthes, The Neutral, trans. Rosalind E. Krauss and Denis Hollier (New York: Columbia U P, 2005) 8.

37. Gilles Deleuze and Félix Guattari, A Thousand Plateaus: Capitalism and Schizophrenia, trans. Brian Massumi. (Minneapolis: U of Minnesota P, 1987) 68.

38. Steven Pinker, How the Mind Works (New York: Norton, 1997) 528.

39. It will seem strange to choose Barthes's work on photography over his work on music, but for my purposes Camera Lucida is much the better resource for formulating the effect of popular music in Wasserstein's play. "The Grain of the Voice," Barthes's most quoted essay on music, compares two post-war art song performers (Dietrich Fischer-Dieskau and Charles Panzéra) using adapted concepts from the work of Julia Kristeva. Her distinction between the pheno-song (the culturally coded dimension of the song) and the geno-song (that aspect of the singing "where significations germinate "from within language and its very materiality"') mirrors in most respects his distinction between studium and punctum in Camera Lucida. But, ironically, only Barthes's theory of photography formulates the involuntary and evocative emotional response so characteristic of popular music. See "The Grain of the Voice," Image-Music-Text, trans. Stephen Heath (New York: Hill and Wang, 1977) 182.

40. Roland Barthes, Camera Lucida: Reflections on Photography, trans. Richard Howard (New York: Hill and Wang, 1982) 26.

41. Barthes, 26, $5 \mathrm{ff}$. 
42. 21.

43. Daniel Levitin, This is Your Brain on Music: The Science of a Human Obsession (New York: Dutton/Penguin, 2006) 179.

44. Herbert Marshall McLuhan, "Hybrid Media," Essential McLuhan, eds. Eric McLuhan and Frank Zingrone (New York: Basic Books, 1995) 278. 